\title{
Liminalitas Pembelajaran Seni Budaya yang Berkelanjutan Dalam Era Digital Native
}

\author{
Ariyan Eka Ramadhana, Haris Supratno, I Nyoman Lodra \\ Program Pascasarjana Pendidikan Seni Budaya, Universitas Negeri Surabaya, \\ Correspondence Email: ariyanekar@gmail.com
}

\begin{abstract}
The development of technology in the digital native era causes the need for adaptation of education, one of which is cultural arts education. It is intended that the art and culture learning process can collaborate and negotiate with native digital technology to improve practical and theoretical skills in the global canon. Therefore, it is necessary to study the limitations of the art and culture learning process in the digital native era. This study also discusses and analyzes the responses of teachers, students, and parents as an ecosystem for the art and culture learning process within the limitations that occur. This research uses a mixedmethods with an interdisciplinary approach to explore educational perspectives, learning methods, technology, which is combined with the liminality conditions of the art and culture learning process in the digital native era. Collecting data using literature and documentation studies, and questionnaires via google form. The spatial boundaries of the research included 10 elementary schools, 10 junior high schools, and 10 high schools in Surabaya, East Java, which were randomly selected. The results showed that (1) the art and culture learning process by utilizing digital native technology has the potential to become sustainable education; (2) provide creative challenges for teachers in delivery, as well as for students in its use; and (3) liminality that occurs in the art and culture learning process occurs in an effort to balance and negotiate between classical and modern learning, practical models and theories, as well as between the orientation of the end result and the orientation of sustainable process outcomes. Therefore, the success of learning cultural arts by utilizing native digital technology requires maturity and understanding of teachers and parents as facilitators regarding policies, facilities, and readiness to integrate them into the pedagogic process.
\end{abstract}

\section{Keywords:}

liminality; the art and culture learning process; continuing education; technology; the native digital era

\begin{abstract}
Abstrak
Perkembangan teknologi dalam era digital native menyebabkan perlunya adaptasi dari pendidikan, salah satunya pendidikan seni budaya. Hal tersebut bertujuan agar pembelajaran seni budaya dapat berkolaborasi dan bernegosiasi dengan teknologi digital native untuk meningkatkan kemampuan secara praktek dan teoritik dalam kanon global. Oleh karenanya, perlu kajian terkait liminalitas pembelajaran seni budaya dalam era digital native. Penelitian ini juga membahas dan menganalisis respons guru, peserta didik, dan orang tua sebagai ekosistem pembelajaran seni budaya dalam liminalitas yang terjadi. Penelitian menggunakan jenis penelitian campuran dan dengan pendekatan interdisiplin untuk mengeksplorasi sudut pandang pendidikan, metode pembelajaran, teknologi, yang dipadukan dengan kondisi liminalitas pembelajaran seni budaya dalam pembelajaran di era digital native. Pengumpulan data menggunakan studi literatur dan dokumentasi, dan kuesioner melalui google form. Batasan spasial penelitian mencakup 10 Sekolah Dasar, 10 Sekolah Menengah Pertama, dan 10 Sekolah Menengah Atas yang berada di Surabaya, Jawa Timur, yang dipilih secara acak. Hasil penelitian menunjukkan bahwa (1) pembelajaran seni budaya dengan memanfaatkan teknologi digital native memiliki potensi untuk menjadi pendidikan berkelanjutan; (2) memberikan tantangan kreativitas bagi guru dalam penyampaian, maupun peserta didik dalam pemanfaatannya; dan (3) liminalitas yang terjadi dalam pembelajaran seni budaya terjadi dalam upaya penyeimbangan dan negosiasi antara pembelajaran klasikal dan modern, model praktek dan teori, serta antara orientasi capaian hasil akhir dan orientasi capaian proses yang berkelanjutan. Oleh karena itu, keberhasilan pembelajaran seni budaya dengan memanfaatkan teknologi digital native memerlukan kematangan dan pemahaman guru dan orang tua sebagai fasilitator terkait kebijakan, fasilitas, dan kesiapan untuk mengintegrasikannya ke dalam proses pedagogik
\end{abstract}




\begin{abstract}
Kata Kunci:
liminalitas; pembelajaran seni budaya; pendidikan berkelanjutan; teknologi; era digital native
\end{abstract}

\section{Pendahuluan}

Pendidikan seni budaya di sekolah merupakan salah satu arena kontestasi peserta didik dalam ranah kreativitas. Pendidikan seni budaya di Indonesia memiliki kecenderungan dalam pembelajaran dengan model praktek ${ }^{1}$. Hal tersebut menjadikan seni budaya sebagai pelajaran yang menyenangkan. Lebih lanjut, seni budaya dianggap sebagai pelajaran yang memiliki kemampuan releasing stress dalam posisinya terhadap mata pelajaran lain di sekolah ${ }^{2}$. Pembelajaran dengan model praktek memberikan kebebasan pada peserta didik untuk berekspresi sehingga memberikan peluang untuk kolaborasi dalam model pembelajaran berbasis permainan, lingkungan, dan sarat unsur terapetik 3 .

Basis model pembelajaran praktek dalam pelajaran seni budaya telah berlangsung sejak lama. Di awal kemunculannya, seni budaya diposisikan sebagai mata pelajaran yang mampu menjadi wadah kreatif peserta didik 4 .

\footnotetext{
${ }^{1}$ Norman Kidi et al., "Android Based Indonesian Information Culture Education Game," Procedia Computer Science 116 (2017): 99-106, https://doi.org/10.1016/j.procs.2017.10.015; Awandi Nopyan Sugiarta, "Pengembangan Model Pengelolaan Program Pembelajaran Kolaboratif Untuk Kemandirian Anak Jalanan Di Rumah Singgah (Studi Terfokus Di Rumah Singgah Kota Bekasi)" (Universitas Pendidikan Indonesia, 2007); Herawati dan Iriaji, Pendidikan Seni Rupa (Jakarta: Direktorat Jenderal Pendidikan Tinggi Departemen Pendidikan dan Kebudayaan, 1998).

2 Muchammad Bayu Tejo Sampurno, "A Case Study of Therapeutic Process Autistic Children as Performing Art in Indonesia," Advances in Social Science, Education and Humanities Research 277, no. Steach $2018 \quad$ (2019): 41-44, https://doi.org/https://doi.org/10.2991/steach18.2019.9; Cathy A. Malchiodi, ed., Handbook of Art Therapy (New York: The Guilford Press, 2003), https://doi.org/10.1176/appi.ps.54.9.1294-a; Olivia
}

Seiring berjalannya waktu, eksplorasi terkait pelajaran seni budaya terus dikembangkan. Namun, model pembelajaran praktek dalam pelajaran seni budaya terus mendominasi dan memberikan legitimasi dalam penyampaiannya. Hal tersebut tidak mereduksi kualitas dari pelajaran seni budaya secara umum, namun, dalam adaptasinya dengan era digital, Internet of Thing (IoT), era disrupsi, revolusi industri 4.0 menuju 5.o, dan dalam menghadapi generasi millenial menuju alpha. Maka perlu adanya negosiasi dalam model penyampaiannya. Negosiasi yang dimaksud adalah positioning pembelajaran seni budaya dalam era digital, Internet of Thing (IoT), era disrupsi, revolusi industri 4.0 menuju 5.0 atau biasa disebut sebagai digital native.

Negosiasi pembelajaran seni budaya dalam era digital native dirasa perlu untuk memperbaharui model mengajar yang berbasis praktikal menuju adaptasi pembelajaran digital. Pembaharuan juga diperlukan dalam mengatasi

Gude, "New School Art Styles: The Project of Art Education," Art Education 66, no. November 2017 (2013): 1-15.

3 Malchiodi, Handbook of Art Therapy; C. Schweizer et al., eds., Handbook of Art Therapy: From the Paint (Houten: Bohn Stafleu Van Loghum, 2009); Daniel H. Bowen, Jay P. Greene, and Brian Kisida, "Learning to Think Critically: A Visual Art Experiment," Educational Researcher 43, no. 1 (2014): 37-44, https://doi.org/10.3102/0013189X13512675.

${ }^{4}$ Leyla Ulusman and Cimen Bayburtlu, "Paradigm for Art Education; Creation Story of Jewels, Theme, Design, Artwork, 3D," Procedia - Social and Behavioral Sciences 51 (2012): 284-88, https://doi.org/10.1016/j.sbspro.2012.08.160; Inés Dussel and Karin Priem, "The Visual in Histories of Education: A Reappraisal," Paedagogica Historica 53, no. 6 (2017): 641-49, https://doi.org/10.1080/00309230.2017.1392582. 
permasalahan model pembelajaran praktikal yang cenderung didominasi pada aspek keterampilan daripada pengetahuan teoritis yang meliputi keilmuan seni budaya, sejarah seni budaya, dan apresiasi seni budaya menjadi kurang terelaborasi dan tereksplorasi 5. Hal tersebut menyebabkan peserta didik kurang mendapatkan sikap apresiasi dalam hal pengetahuan seni budaya, sejarah seni budaya, dan apresiasi seni budaya Indonesia. Oleh karenanya, dalam proses regenerasi pemerhati budaya dalam generasi muda menjadi tidak optimal ${ }^{6}$.

Pembelajaran seni budaya di era digital native dituntut untuk memiliki aspek keberlanjutan 7. Artinya, pemanfaatan pelajaran seni budaya tidak hanya terlihat saat di dalam kelas atau di saat pelajaran berlangsung, namun juga di lingkungan luar sekolah dan dalam kehidupan peserta didik sehari-hari. Berkaitan dengan hal tersebut, dengan mempertimbangkan kompleksitas pelajaran seni budaya dan pembelajarannya, serta perkembangan

5 Jen Ross, "Speculative Method in Digital Education Research," Learning, Media and Technology 42, no. 2 (2017): 214-29, https://doi.org/10.1080/17439884.2016.1160927;

Roger D. Gehlbach, "Art Education: Issues in Curriculum and Research," Educational Researcher 19, no. 7 (1990): https://doi.org/10.3102/0013189X019007019;

Susanna Lindberg, "Politics of Digital LearningThinking Education with Bernard Stiegler," Educational Philosophy and Theory 52, no. 4 (2020): 384-96,

https://doi.org/10.1080/00131857.2019.1586531; Oscar Rantatalo and Ola Lindberg, "Liminal Practice and Reflection in Professional Education: Police Education and Medical Education," Studies in Continuing Education 40, no. 3 (2018): 351-66, https://doi.org/10.1080/0158037X.2018.1447918.

${ }^{6}$ Shiming Gao and Chih ming Wang, "Crisis of the Human and the Responsibilities of Art/Education," Inter-Asia Cultural Studies 20, no. 1 (2019): 140-49, https://doi.org/10.1080/14649373.2019.1577586.

7 Dussel and Priem, "The Visual in Histories of Education: A Reappraisal." teknologi dan kampanye pelajaran seni budaya dalam era digital native, maka pemanfaatan teknologi perlu dielaborasi dan dieksplorasi lebih lanjut. Hal tersebut untuk memosisikan pelajaran seni rupa dalam liminalitas dalam era digital native.

Pemanfaatan teknologi digital dalam pembelajaran seni budaya dianggap penting untuk memberikan kesempatan bagi pendidik dan siswa untuk beroperasi dalam dunia digital. Teknologi digital dapat mendukung pembelajaran seni budaya di berbagai aspek dan memberikan peluang untuk komunikasi yang efektif antara guru dan peserta didik dengan cara yang baru 8 . Terlebih lagi di abad 21 ini teknologi menjadi isu penting dalam berbagai bidang termasuk pendidikan 9. Hal tersebut dikarenakan teknologi telah menjadi trayektori utama dalam transfer pengetahuan di berbagai negara dunia sehingga mempengaruhi pola pikir masyarakat terkait pentingnya teknologi.

Integrasi teknologi saat ini telah melalui inovasi dan mentransformasi masyarakat dalam cara berpikir, bekerja,

8 Alison Colman, "Net.Art and Net.Pedagogy: Introducing Internet Art to the Digital Art Curriculum," Studies in Art Education 46, no. Technology Issue (2018): 61-73; Pedro Gomis-Porqueras and José A. Rodrigues-Neto, "Teaching Technologies, Attendance, Learning and the Optimal Level of Access to Online Materials," Economic Modelling 73, no. May 2017 (2018): $329-42$, https://doi.org/10.1016/j.econmod.2018.04.009; Pamela G Taylor and B Stephen Carpenter, "Mediating Art Education : Digital Kids , Art , and Technology," Visual Arts Research 33, no. 2 (2016): 84-95.

9 J. Kevin Maney, "The Role of Technology in Education," Handbook of Educational Policy, no. January (1999): 387-415, https://doi.org/10.1016/b978-012174698-8/50043-6; Kathy Ann Mills, "A Review of the " Digital Turn " in the New Literacy Studies," Review of Educational Research 80, no. 2 (2016): 246-71; Tzu-Bin Lin, Victor Chen, and Ching Sing Chai, eds., New Media and Learning in the 21st Century; A Social-Cultural Perspective (Singapore: Springer, 2015), https://doi.org/10.1007/978-981-287-326-2. 
dan menjalani kehidupan 10. Sebagai bagian dari teknologi, sekolah atau lembaga pendidikan lain yang diharapkan mempersiapkan peserta didik untuk hidup dalam "masyarakat intelektual", perlu mempertimbangkan integrasi teknologi dan liminalitas pembelajaran seni budaya terhadapnya 11. Liminalitas pembelajaran seni budaya terhadap teknologi mengacu pada penggunaan komunikasi berbasis komputer, aplikasi, atau internet yang digabungkan ke dalam proses pembelajaran seni budaya 12. Oleh karenanya, perlu kajian terkait liminalitas pembelajaran seni budaya dalam era digital native. Penelitian ini juga membahas dan menganalisis respons guru, peserta didik, dan orang tua sebagai ekosistem pembelajaran seni budaya dalam liminalitas yang terjadi.

Untuk menjawab, mengkaji, dan menegksplorasi terkait permasalahan di atas, maka diperlukan metode dalam penelitian sebagai trajektori akademik. Penelitian ini menggunakan metode kualitatif analitik dan dibantu dengan sedikit konsep dari penelitian kuantitatif

${ }^{10}$ Haeryun Choi and Joseph M. Piro, "Expanding Arts Education in a Digital Age," Arts Education Policy Review 110, no. 3 (2009): 27-34, https://doi.org/10.3200/AEPR.110.3.27-34; Danah Henriksen, Punya Mishra, and Petra Fisser, "International Forum of Educational Technology \& Society Infusing Creativity and Technology in $21 \mathrm{st}$ Century Education: A Systemic View for Change Published by: International Forum of Educational Technology \& Society Infusing Creativity and Technology In," Journal of Educational Technology \& Society 19, no. 3 (2016): 27-37.

${ }^{11}$ Choi and Piro, "Expanding Arts Education in a Digital Age"; Elizabeth Grierson, "Art and Creativity in the Global Economies of Education," Educational Philosophy and Theory 43, no. 4 (2011): 336-50, https://doi.org/10.1111/j.1469-5812.2009.00550.x;

Vicky Gunn, "Attentive Outrage and Fine Art Higher Education: A Manifesto of the Liminal," Journal of Visual Art Practice 19, no. 1 (2020): 8-22, https://doi.org/10.1080/14702029.2020.1723278;

Rantatalo and Lindberg, "Liminal Practice and Reflection in Professional Education: Police Education and Medical Education." dalam pengumpulan data, oleh karenanya penelitian ini merupakan jenis penelitian campuran 13. Pendekatan interdisiplin dipilih karena peneliti ingin mengeksplorasi sudut pandang pendidikan, metode pembelajaran, teknologi, yang dipadukan dengan kondisi liminalitas pembelajaran seni budaya dalam pembelajaran di era digital native14. Pengumpulan data menggunakan studi literatur, dokumentasi, dan kuesioner, dengan rincian (1) studi dokumentasi terhadap kecenderungan pembelajaran seni budaya dari penelitian dan observasi lapangan pada 30 sekolah (10 Sekolah Dasar, 10 Sekolah Menengah Pertama, dan 10 Sekolah Menengah Atas) di Surabaya, Jawa Timur, dengan kriteria pemilihan lokasi menggunakan teknik random sampling; (2) kuesioner terhadap guru dan peserta didik terkait pembelajaran seni budaya dan teknologi digital native, di mana kuesioner dilakukan melalui platform google form selama Juli 2019 hingga Mei 2020, sesuai dengan waktu penelitian. Setelahnya, data yang terkumpul akan dianalisis secara

\footnotetext{
12 Rantatalo and Lindberg, "Liminal Practice and
} Reflection in Professional Education: Police Education and Medical Education."

13 A Tashakkori and J Creswell, "Mixed Methodology Across Disciplines," Journal Of Mixed Methods Research 2, no. 1 (2008): 1-5; Particia Leavy, Research Design: Quantitative, Qualitative, Mixed Methods, Arts-Based, and Community-Based Participatory Research Approaches (New York: The Guilford Press, 2017); John W Creswell, Research Design Pendekatan Kualitatif, Kuantitatif, Dan Mixed (Yogyakarta: Pustaka Pelajar, 2010).

14 Joe Moran, Interdisciplinarity (New York: Routledge, 2002); Leavy, Research Design: Quantitative, Qualitative, Mixed Methods, Arts-Based, and Community-Based Participatory Research Approaches; Norman K. Denzin and Yvonna S. Lincoln, eds., The SAGE Handbook of Qualitative Research, Fifth Edit (Los Angeles: Sage Publications, 2018), https://doi.org/10.1007/s11229-017-1319-x; Howard Lune and Bruce L. Berg, Qualitative Research Methods for the Social Sciences, Ninth edit (Essex: Pearson, 2017). 
deskriptif untuk mengeksplorasi tentang liminalitas pembelajaran seni budaya yang berkelanjutan di era digital native.

\section{Hasil dan Pembahasan}

Globalisasi

meningkatnya

merepresentasikan

ketergantungan, keterkaitan, dan integrasi dunia terhadap arus global. Globalisasi, dan selanjutnya teknologi, telah menjadi kekuatan pendorong dalam pengembangan kebijakan pendidikan di era digital native ${ }^{15}$. Sebagian besar sistem sekolah di dunia mengubah kurikulum dan kebijakan instruksional mereka untuk memastikan bahwa siswa cukup "mengglobal" dan mampu bersaing di berbagai sektor dalam kancah digital native 16. Keterampilan yang diperlukan dalam era digital native adalah pembacaan visual dan daya pemikiran kritis dan eksploratif terkait seni budaya, oleh karenanya pendidikan seni budaya menempati posisi sentral dalam era digital native 17. Hal tersebut didukung dengan argumentasi yang mengatakan keterampilan lain yang disebut-sebut secara khusus relevan dengan abad 21 dan era digital native adalah berpikir kritis, pemecahan masalah, komunikasi, kolaborasi, kreativitas, literasi media, dan keahlian

15 Ryan M. Patton and Melanie L. Buffington, "Keeping up with Our Students: The Evolution of Technology and Standards in Art Education," Arts Education Policy Review 117, no. 3 (2016): 1-9, https://doi.org/10.1080/10632913.2014.944961.

${ }^{16}$ Simin Ghavifekr and Wan Athirah Wan Rosdy, "Teaching and Learning with Technology: Effectiveness of ICT Integration in Schools," International Journal of Research in Education and Science 1, no. 2 (2015): 175-91, https://doi.org/10.21890/ijres.23596.

17 Anne Morgan Spalter and Andries Van Dam, "Digital Visual Literacy," Theory into Practice 47, no. 2 (2008): 93-101, https://doi.org/10.1080/00405840801992256; Troy Hicks and Kristen Hawley Turner, "No Longer a Luxury: Digital Literacy Can't Wait," The English Journal 102, no. 6 (2013): 58-65, https://doi.org/10.4135/9781412957403.n296. lintas budaya 18. Dengan latar belakang ini, menjadikan literasi pemanfaatan teknologi digital native menjadi faktor berkeyakinan bahwa seni budaya memiliki peran penting dalam peningkatan kemampuan peserta didik 19. Namun kesulitannya adalah melepaskan seni budaya dari legitimasi arus mainstream yang mengatakan bahwa seni budaya hanyalah pelengkap dari bidang lainnya. Oleh karena itu, dalam kerangka pemikiran inilah seni budaya harus menemukan kembali dirinya sebagai jalan untuk membantu mempertahankan budaya inovasi yang semakin penting dalam kaitannya dengan era digital native, sehingga dapat membantu menentukan signifikansi seni budaya di masa depan dan memastikan tempat mereka dalam kanon pendidikan dunia.

Berkaitan dengan hal tersebut, pendidikan selalu berkembang dalam teori, model, capaian, dan aplikasinya dalam rangka mempersiapkan peserta didik menghadapi era digital native, termasuk pendidikan seni budaya. Demi mencapai tujuan dengan baik, maka guru dipandang sebagai titik sentral dalam pemanfaatan teknologi digital native dalam pembelajaran seni budaya yang berkelanjutan. Hal ini dikarenakan

18 Margaret Slota et al., "Visual Intelligence Education as an Innovative Interdisciplinary Approach for Advancing Communication and Collaboration Skills in Nursing Practice," Journal of Professional Nursing 34, no. 5 (2018): 357-63, https://doi.org/10.1016/j.profnurs.2017.12.007;

Marissa McClure et al., "Defining Quality in Visual Art Education for Young Children: Building on the Position Statement of the Early Childhood Art Educators," Arts Education Policy Review 118, no. 3 (2017): $154-63$, https://doi.org/10.1080/10632913.2016.1245167;

Bowen, Greene, and Kisida, "Learning to Think Critically: A Visual Art Experiment."

19 Csilla Weninger, "The 'Vernacularization' of Global Education Policy: Media and Digital Literacy as Twenty-First Century Skills in Singapore," Asia Pacific Journal of Education 37, no. 4 (2017): 500516, https://doi.org/10.1080/02188791.2017.1336429. 
kemampuan teknologi digital native dalam menyediakan lingkungan belajar yang dinamis dan proaktif ${ }^{20}$. Sementara itu, tujuan integrasi teknologi digital native dalam pembelajaran seni budaya adalah untuk meningkatkan dan meningkatkan kualitas, aksesibilitas dan efisiensi biaya penyampaian pengajaran kepada peserta didik, yang juga mengacu pada manfaat dari jaringan digital native untuk menghadapi tantangan globalisasi saat ini ${ }^{21}$. Proses adopsi teknologi digital native dalam pembelajaran seni budaya tidak dicapai dengan singkat, namun merupakan langkah berkelanjutan yang mendukung pengajaran dan pembelajaran dalam kompleksitas sumber pengetahuan yang dimiliki oleh teknologi digital native 22.
Integrasi teknologi digital native dalam pembelajaran seni budaya erat kaitannya dengan pemanfaatan teknologi pembelajaran di sekolah. Peserta didik yang berada pada generasi milenial sudah mengenal teknologi dan mereka akan belajar lebih baik dalam lingkungan berbasis teknologi, oleh karenanya perlu persiapan pemahaman terkait teknologi digital native di sekolah. Hal ini dikarenakan, pemanfaatan teknologi digital native dalam dunia pendidikan memberikan kontribusi yang besar pada aspek pedagogis dimana penerapan teknologi digital native dalam pembelajaran seni budaya akan mengarah pada pembelajaran yang efektif dengan bantuan dan dukungan dari era IoT ${ }^{23}$.

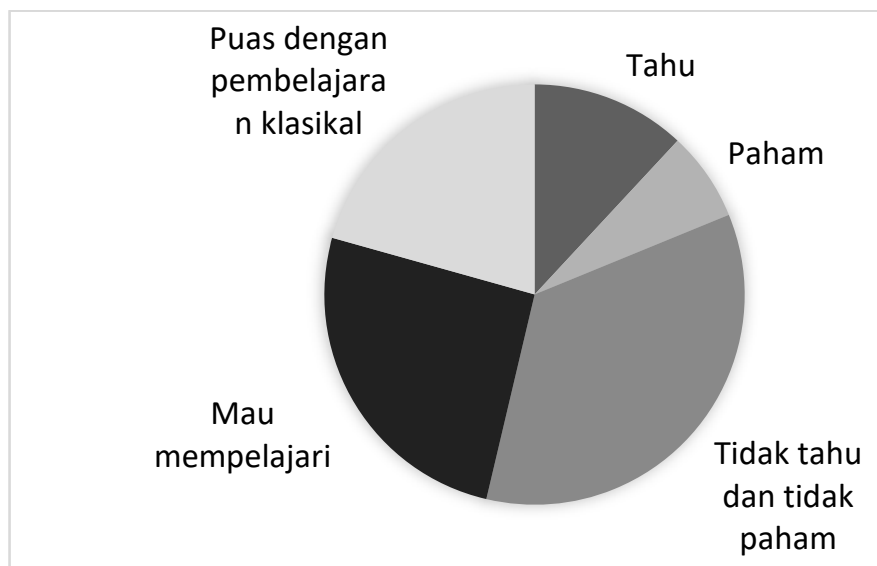

Tabel 1. Persepsi guru terhadap inovasi dan penyesuaian pembelajaran dalam era digital native

20 Allan Martin, Digital Literacy and the Digital Society (Dutch: Die Deutsche Bibliothek, 2008); Weninger, "The 'Vernacularization' of Global Education Policy: Media and Digital Literacy as Twenty-First Century Skills in Singapore"; Spalter and Van Dam, "Digital Visual Literacy."

21 Joanna Black and Kathy Browning, "Creativity in Digital Art Education Teaching Practices," Art Education 64, no. 5 (2011): 19-34, https://doi.org/10.1080/00043125.2011.11519140;

E.S. Pianfetti, "Teachers and Technology: Digital Literacy through Professional Development," Language Arts 78, no. 255-262 (2001): 255-62; Choi and Piro, "Expanding Arts Education in a Digital Age."

22 Vuyisile Msila and Angeline Setlhako, "Teaching (Still) Matters: Experiences on Developing a Heutagogical Online Module at UNISA," Procedia Social and Behavioral Sciences 69, no. Iceepsy 2012 (2012): 136-42, https://doi.org/10.1016/j.sbspro.2012.11.392;

Ghavifekr and Rosdy, "Teaching and Learning with Technology: Effectiveness of ICT Integration in Schools."

${ }^{23}$ Lorna R. Kearns, "The Experience of Teaching Online and Its Impact on Faculty Innovation across Delivery Methods," Internet and Higher Education 31 (2016): 71-78, https://doi.org/10.1016/j.iheduc.2016.06.005; I. Ketut Sudarsana et al., "Technology Application in Education and Learning Process," Journal of Physics: Conference Series 1363, no. 1 (2019), https://doi.org/10.1088/1742-6596/1363/1/012061. 
Kesiapan guru dalam mengelola dikarenakan legitimasi model pembelajaran seni budaya perlu perhatian pembelajaran praktek yang biasa secara mendalam, karena sebagian besar dilakukan pada pelajaran seni budaya. guru belum siap terhadap pemanfaatan Lebih lanjut, perubahannya serta teknologi digital native dalam pemahaman konsep liminalitas oleh guru pembelajaran seni budaya. Hal tersebut dan bahkan sekolah belum maksimal.

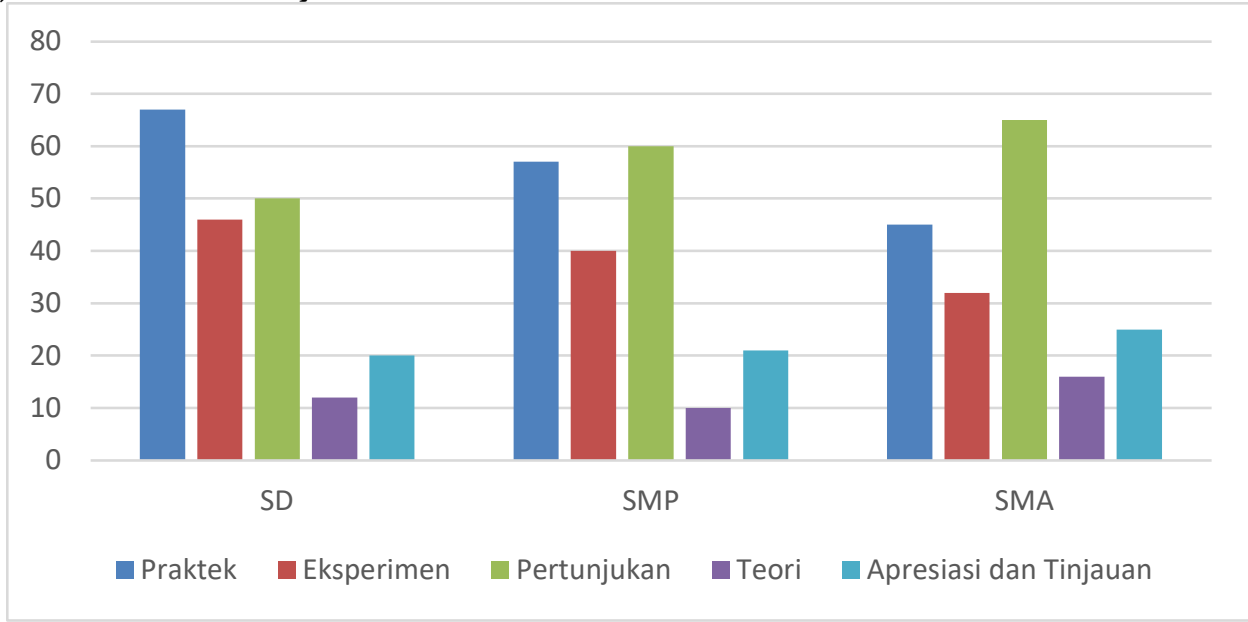

Tabel 2. Perbandingan model pembelajaran seni budaya di sekolah

Teknologi digital native dalam pembelajaran seni budaya memberikan bantuan bagi guru dan peserta didik dimana hal tersebut melibatkan pembelajaran yang efektif dengan bantuan teknologi dan jaringan internet untuk memenuhi tujuan serta capaian pembelajaran ${ }^{24}$. Seperti Halnya pemahaman peserta didik terhadap materi ilmu dan teori seni, sejarah seni, apresiasi seni dan budaya, tinjauan seni dan budaya, dapat dimaksimalkan dengan negosiasi antara teknologi digital native dan pembelajaran seni budaya klasikal. Lebih lanjut, permasalahan terkait ketidakpahaman peserta didik tentang materi yang berkaitan dengan teori seni budaya tersebut dapat diakomodasi dengan pemanfaatan teknologi digital native.

\footnotetext{
${ }^{24}$ Kyungmee Lee, "Rethinking the Accessibility of Online Higher Education: A Historical Review," Internet and Higher Education 33 (2017): 15-23,

https://doi.org/10.1016/j.iheduc.2017.01.001; Taylor and Carpenter, "Mediating Art Education : Digital Kids , Art , and Technology."
} 


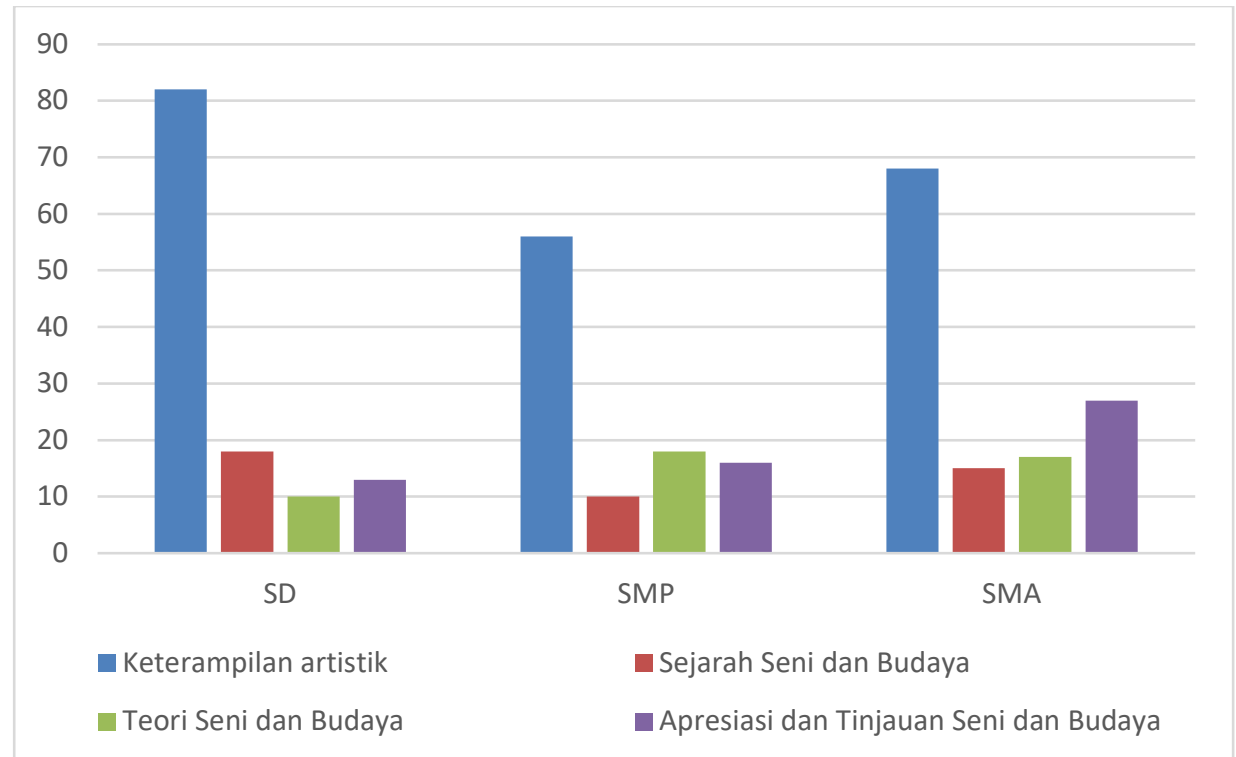

Tabel 3. Pemahaman dan ketertarikan peserta didik terhadap materi seni budaya

Liminalitas pembelajaran seni budaya dalam era digital native memposisikan teknologi tidak bertindak sebagai alat pengganti bagi guru tetapi dianggap sebagai pelengkap tambahan yang diperlukan untuk pengajaran dan pembelajaran yang lebih baik. Integrasi teknologi digital native dalam pembelajaran seni budaya sangat penting, karena dengan bantuan teknologi digital native, proses belajar mengajar tidak hanya terjadi di lingkungan sekolah, tetapi juga dapat terjadi walaupun guru dan peserta didik secara fisik berada dalam jarak yang jauh dan berkelanjutan. Teknologi digital native dapat digunakan dalam fleksibilitas model pembelajaran untuk mempelajari materi dalam pelajaran seni budaya. Pembelajaran seni budaya berbasis teknologi digital native menawarkan berbagai cara menarik yang meliputi video pendidikan, stimulasi, simulasi atau tutorial, data visual, pemanfaatan database seni budaya, serta pemetaan pikiran secara daring, yang akan membuat proses pembelajaran lebih maksimal ${ }^{25}$. Disisi lain, peserta didik akan mendapatkan keuntungan dari integrasi teknologi digital native di mana mereka tidak terikat pada model klasikal dan dengan sumber daya yang terbatas. Sebaliknya, proses belajar dialami secara langsung dalam basis teknologi sehingga membantu peserta didik dalam merangsang pemahaman tentang seni budaya Indonesia. Peserta didik merasa nyaman dalam integrasi teknologi digital native dalam pembelajaran seni budaya. Fleksibilitas dan kompleksitas yang dimiliki teknologi digital native membantu lancarnya pembelajaran dan mendukung terwujudnya capaian pembelajaran.
${ }^{25}$ Choi and Piro, "Expanding Arts Education in a Digital Age"; Robert D. Quinn, "E-Learning in Art Education: Collaborative Meaning Making Through Digital Art Production," Art Education 64, no. 4
(2018): 18-24; Slota et al., "Visual Intelligence Education as an Innovative Interdisciplinary Approach for Advancing Communication and Collaboration Skills in Nursing Practice." 
675 | Naturalistic: Jurnal Kajian Penelitian dan Pendidikan dan Pembelajaran, Volume 5 Issue 1, Oktober 2020 Hal $667-683$

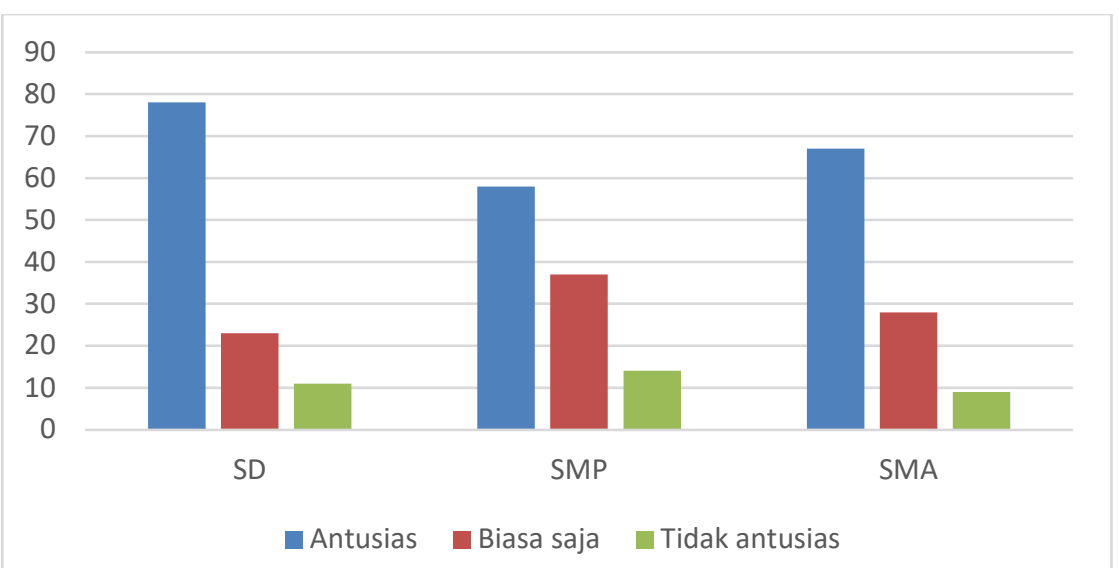

Tabel 4. Persepsi peserta didik terhadap integrasi teknologi digital native dalam pembelajaran seni budaya

Teknologi digital native juga membantu guru untuk merancang rencana pembelajaran seni budaya dengan pendekatan yang efektif, kreatif dan menarik yang akan menghasilkan pembelajaran aktif. Penelitian sebelumnya membuktikan bahwa penggunaan teknologi digital native dalam pengajaran akan meningkatkan proses pembelajaran dan memaksimalkan kemampuan peserta didik dalam pembelajaran aktif ${ }^{26}$. Integrasi terhadap teknologi digital native dalam pembelajaran seni budaya adalah tentang penerapan penggunaan teknologi digital native yang melibatkan konsep dan keterampilan yang kompleks untuk meningkatkan prestasi dan pencapaian peserta didik.

Pembelajaran seni budaya berbasis teknologi digital native dapat membuat banyak perubahan di sekolah membutuhkan perencanaan pendidikan yang baik. Salah satunya dengan penyamaan persepsi terkait dasar

26 Wycliff Edwin Tusiime, Monica Johannesen, and Greta Björk Gudmundsdottir, "Teaching Art and Design in a Digital Age: Challenges Facing Ugandan Teacher Educators," Journal of Vocational Education and Training, 2020 , https://doi.org/10.1080/13636820.2020.1786439; Pianfetti, "Teachers and Technology: Digital Literacy through Professional Development"; Choi and Piro, "Expanding Arts Education in a Digital Age"; Tipton pemikiran, tujuan, dan visi tentang bagaimana sistem pendidikan berjalan ketika teknologi digital native diintegrasikan ke dalam proses belajar. Lebih lanjut, perlu ditekankan terkait kebermanfaatannya bagi siswa, guru, orang tua dan masyarakat umum dalam cakupan seni budaya dan relasinya dengan disiplin lain.

Perkembangan teknologi pembelajaran di akhir abad ke-2o secara tidak langsung memaksa sistem pendidikan untuk berubah dengan cepat 27. Hal ini disebabkan oleh kapabilitas teknologi digital native untuk menyediakan lingkungan belajar seni budaya yang proaktif, mudah, dan komprehensif. Saat ini, paradigma pendidikan menganggap teknologi digital native menyediakan banyak fasilitas dalam pemanfaatan teknologi digital native dalam proses belajar. Hal tersebut membutuhkan peran guru untuk semakin aktif terutama dalam penggunaan teknologi digital native dalam pedagogi

D. Hudson, "Conversation as an Education Medium for the Age of Distraction - the 'Art of Range' Podcast," Rangelands 42, no. 1 (2020): 9-16, https://doi.org/10.1016/j.rala.2020.01.005; Colman, "Net.Art and Net.Pedagogy: Introducing Internet Art to the Digital Art Curriculum."

${ }^{27}$ Mills, "A Review of the " Digital Turn " in the New Literacy Studies." 
yang dapat meningkatkan prestasi, kreativitas, dan kemampuan berpikir peserta didik dengan basis seni budaya. Lebih lanjut, peserta didik di sekolah memiliki harapan yang tinggi pada integrasi teknologi digital native karena mereka tergolong sebagai generasi milenial yang lahir dan tumbuh bersama teknologi dan dapat digolongkan sebagai generasi digital native.

Perkembangan teknologi dan munculnya era serta generasi digital native memposisikan pendidikan seni budaya dalam posisi sentral, yaitu dalam liminalitas terhadap perkembangan arus global. Ruang liminal dapat dilihat sebagai ruang transformatif yang terjadi ketika hal-hal seperti pemikiran, pengetahuan, atau ide dinegosiasikan sehingga menjadi entitas yang cair dan fleksibel. Ruang di antara itu adalah keadaan liminalitas, di mana transisi dalam proses pembelajaran seni budaya melintasi ambang batas dan saling menyeimbangkan dengan bidang, aspek, atau faktor di sekitarnya 28 .

Pembelajaran seni budaya sebagai sebuah konsep liminal berasal dari fase liminalitas yang didefinisikan dalam pemisahan (yaitu pelepasan dari kondisi budaya), limen (pergerakan dan transisi antara struktur sosial) dan agregasi (fase penyempurnaan yang bersifat kolaboratif) 29. Liminalitas dalam penelitian ini

${ }^{28}$ Alison Cook-Sather and Zanny Alter, "What Is and What Can Be: How a Liminal Position Can Change Learning and Teaching in Higher Education," Anthropology and Education Quarterly 42, no. 1 (2011): 37-53, https://doi.org/10.1111/j.15481492.2010.01109.x; Rantatalo and Lindberg, "Liminal Practice and Reflection in Professional Education: Police Education and Medical Education."

${ }^{29}$ Rantatalo and Lindberg, "Liminal Practice and Reflection in Professional Education: Police Education and Medical Education"; McClure et al., "Defining Quality in Visual Art Education for Young Children: Building on the Position Statement of the Early Childhood Art Educators"; Slota et al., "Visual Intelligence Education as an Innovative Interdisciplinary Approach for Advancing memiliki makna tentang pembelajaran seni budaya yang diterapkan dengan fokus pada 'ruang/waktu transisi' sebagai fase limen, yang memungkinkan individu atau kelompok untuk memperoleh identitas, status atau pengetahuan baru dengan meninggalkan posisi legitimasi atau arus mainstream 30.

Integrasi teknologi digital native dalam pembelajaran seni budaya memberikan kesempatan untuk lebih menyeimbangkan antara teoritik dan praktik 31. Hal tersebut berkaitan dengan negosiasi yang disalurkan melalui praktik eksperimen berbasis pengetahuan dan pemahaman yang bersifat teoritis. Praktik-praktik juga dilakukan bukan hanya dalam sudut pandang artistik, namun juga identitas dengan tindakan reflektif, di mana identitas dikembangkan melalui pertanyaan tentang positioning pendidikan seni budaya dalam kancah global. Liminalitas mirip dengan konseptualisasi ruang, yang menekankan bagaimana ruang dibentuk melalui pemberlakuan dan pembiasaan ${ }^{32}$. Oleh karenanya, liminalitas hadir sebagai katarsis negosiasi dalam hubungan antara generasi dan teknologi digital native dan pembelajaran seni budaya. Ruang liminal juga diposisikan sebagai metafora untuk menggambarkan keadaan di mana peserta didik mengalami dalam apropriasi 'konsep

Communication and Collaboration Skills in Nursing Practice."

${ }^{30}$ Gunn, "Attentive Outrage and Fine Art Higher Education: A Manifesto of the Liminal"; Cook-Sather and Alter, "What Is and What Can Be: How a Liminal Position Can Change Learning and Teaching in Higher Education."

${ }^{31}$ Craig Roland, "Preparing Art Teachers to Teach in a New Digital Landscape," Art Education 63, no. 1 (2010):

17-24, https://doi.org/10.1080/00043125.2010.11519049;

Christine Ballengee Morris, "Art Education in Transition," Art Education 64, no. 5 (2011): 7-9.

${ }^{32}$ Cook-Sather and Alter, "What Is and What Can Be: How a Liminal Position Can Change Learning and Teaching in Higher Education." 
ambang' untuk memperoleh pandangan baru.

Liminalitas tahap awal terjadi ketika guru dan peserta didik menemukan hambatan integrasi digital native di pembelajaran seni budaya adalah tentang kepercayaan diri, kompetensi, dan sikap kreatif melalui keterampilan. Di dalam liminalitasnya, seni budaya berperan sebagai negosiator dan penyeimbang terhadap global dan lokal, teknologi dan klasikal, serta antara teoretik dan praktik 33. Salah satu caranya dengan memanfaatkan literasi visual sebagai negosiator dan penyeimbang dalam pemanfaatan teknologi digital native dalam pembelajaran seni budaya. Literasi visual adalah konsep pembelajaran seni budaya berbasis teknologi digital native yang memanfaatkan sekumpulan kompetensi pembelajaran yang dapat dikembangkan dengan melihat sekaligus memiliki dan mengintegrasikan pengalaman inderawi lainnya 34. Pengembangan kompetensi ini merupakan dasar pembelajaran seni budaya yang memungkinkan peserta didik untuk membiasakan pemikiran kritis terhadap objek atau simbol yang ditemui dalam teknologi digital native yang memiliki relasi dengan lingkungannya 35 . Melalui penggunaan kompetensi ini secara apresiatif, liminalitas seni budaya

${ }^{33}$ Morris, "Art Education in Transition"; Laurie E Hicks, "Art Education: Thing or Device," Studies in Art Education 54, no. 2 (2019): 99-102.

34 Spalter and Van Dam, "Digital Visual Literacy"; Slota et al., "Visual Intelligence Education as an Innovative Interdisciplinary Approach for Advancing Communication and Collaboration Skills in Nursing Practice"; Andres Gabriel Villamizar, "Examining Intersections between Visual Literacy and Digital Technologies in English Language Programs for Higher Education," Journal of Visual Literacy 37, no. 4 (2018): 276-93, https://doi.org/10.1080/1051144X.2018.1522089.

${ }^{35}$ Gunther Kress and Theo van Leeuwen, Reading Images: The Grammar of Visual Design (London: mampu memahami dan menikmati produk seni budaya secara komprehensif.

Di dalam proses peningkatan kemampuan berpikir kritis, literasi visual melibatkan seperangkat keterampilan yang berkisar dari sekadar mengidentifikasi apa yang dilihat dalam sebuah gambar, sehingga menafsirkan kompleksitas seperti kontekstualitas dan konseptualisasi fenomena, serta alasan empirik maupun estetik dari produk seni budaya 36 . Sejalan dengan itu, literasi visual mencakup pengembangan keterampilan yang diperlukan untuk menafsirkan konten gambar, untuk memahami dampaknya terhadap masyarakat, dan untuk secara kritis mendiskusikan alasan di balik pembuatannya. Lebih lanjut, dengan literasi visual, peserta didik mampu memvisualisasikan secara internal sesuai dengan sudut pandangnya, berkomunikasi secara visual, dan membaca dan menafsirkan gambar visual. Hal tersebut memberikan keseimbangan dalam intelektualitas dan praktek sehingga liminalitas dalam pembelajaran seni budaya sejalan dengan capaian pembelajaran.

Hubungan triadik antara teknologi digital native, literasi visual, dan pembelajaran seni budaya hanya mengeksplorasi kemampuan untuk memecahkan kode dan menafsirkan pesan

Routledge, 2012); Villamizar, "Examining Intersections between Visual Literacy and Digital Technologies in English Language Programs for Higher Education."

${ }^{36}$ Villamizar, "Examining Intersections between Visual Literacy and Digital Technologies in English Language Programs for Higher Education"; Slota et al., "Visual Intelligence Education as an Innovative Interdisciplinary Approach for Advancing Communication and Collaboration Skills in Nursing Practice"; Michelle Cannon, Digital Media in Education: Teaching, Learning and Literacy Practices with Young Learners (London: The Palgrave Macmillan, 2018), https://doi.org/10.1007/978-3-31978304-8. 
visual tetapi juga meningkatkan kapasitas untuk melakukan koding dan membuat komunikasi visual secara detail 37. Hal tersebut memerlukan tingkat berpikir kritis yang tinggi, sehingga berimplikasi pada peningkatan kreativitas peserta didik. Menurut The Association of College and Research Libraries (ACRL) peserta didik yang memiliki daya kritis dalam literasi visual mampu 1) memiliki sudut pandang yang luas terhadap materi visual berbasis budaya, 2) mengaplikasikan data visual dengan basis budaya dengan efektif dan efisien, 3) mampu menafsirkan, mengkaji, dan menganalisis makna gambar dan media visual dengan basis budaya, 5) memahami masalah terkait etika, hukum, sosial, dan ekonomi seputar pembuatan dan penggunaan gambar dan media visual secara multiperspektif dengan menggunakan pendekatan interdisiplin 38. Standar yang diuraikan tersebut menjadi faktor esensial dalam liminalitas dan hubungan triadik antara teknologi digital native, literasi visual, dan pembelajaran seni budaya.

Kress dan van Leewen berpendapat bahwa perhatian guru untuk mengembangkan keterampilan literasi visual peserta didik menurun saat mereka tumbuh dewasa 39. Legitimasi terhadap model praktek dalam pembelajaran seni budaya memiliki kecenderungan guru hanya mendorong peserta didik untuk membuat gambar dan berorientasikan pada hasil akhirnya saja. Guru tidak menilai dengan detail terkait proses berkarya dan bagaimana peserta didik mengolah data visual yang diperoleh sebelum menjadikannya sebuah karya seni. Hal tersebut menyebabkan kurang

\footnotetext{
${ }^{37}$ Bowen, Greene, and Kisida, "Learning to Think Critically: A Visual Art Experiment."

38 Association of College and Research Libraries (ACRL), "ACRL Visual Literacy Competency Standards for Higher Education," 2011, http://www.ala.org/acrl/standards/visualliteracy.
}

terlatihnya peserta didik dalam bertanggung jawab terhadap karya seni yang dibuatnya. Teknologi digital native dalam pembelajaran seni budaya memberikan ruang yang berkenaan dengan memori digital 40. Guru dan siswa dapat membuat pengarsipan digital dengan mengunggah karya-karya peserta didik ke dalam platform digital, sehingga mampu diapresiasi oleh masyarakat luas. Hal tersebut memberikan tantangan kepada peserta didik untuk membuat karya dengan maksimal disertai dengan data empirik yang mendasari karya seni terbentuk. Pada saat peserta didik mencapai esensi dari pendidikan seni budaya, maka mereka mendapatkan pengetahuan baik secara kemampuan artistik (keterampilan teknis) maupun pengalaman estetik, dibandingkan hanya sekadar menjadi media ekspresi diri. Oleh karenanya, integrasi tersebut memberikan penekanan tentang pentingnya liminalitas pembelajaran seni budaya berkelanjutan. Konsep berkelanjutan merupakan konsep kontinuitas dalam belajar dan pengaplikasiannya, sehingga materi yang diperoleh peserta didik dapat diaplikasikan dan bermanfaat dalam mengatasi permasalahan dalam kehidupan sehari-hari. Keterampilan literasi visual abad ke-21 memberikan kemampuan menganalisis dan menghasilkan karya seni secara kritis, memahami karakteristik estetika budaya setempat, mengkomunikasikan pesan yang dimaksudkan baik secara visual maupun teoritik, dan mampu mengevaluasinya terhadap konteks sosiobudaya.

39 Kress and Leeuwen, Reading Images: The Grammar of Visual Design.

40 Steve Charman and Brian Cahill, "Journal of Applied Research in Memory and Cognition," Journal of Applied Research in Memory and Cognition 1, no. 220020483 (2012): 171-78. 


\section{Simpulan}

Perkembangan teknologi yang tidak bisa dihindari memberikan peran penting dalam perkembangan model pembelajaran generasi millenial. Pemanfaatan teknologi dalam pembelajaran seni budaya dengan semangat digital native memiliki potensi untuk menjadi pendidikan berkelanjutan. Selain itu, dapat memberikan tantangan kreativitas bagi guru dalam penyampaian, maupun peserta didik dalam pemanfaatannya. Hal tersebut dipengaruhi oleh liminalitas yang terjadi dalam pembelajaran seni budaya yang terjadi dalam upaya penyeimbangan dan negosiasi antara pembelajaran klasikal dan modern, model praktek dan teori, serta antara orientasi capaian hasil akhir dan orientasi capaian proses yang berkelanjutan.

Keberhasilan dari pembelajaran memanfaatkan digital native dipengaruhi beberapa elemen yang saling terintegrasi dan mendukung. Pertama, adanya integrasi antara orang tua dan peserta didik. Orang tua membutuhkan edukasi, penjelasan, pemahaman, dan bahkan pelatihan terkait pemanfaatan teknologi digital native dalam pembelajaran. Hal ini sejalan dengan upaya reorientasi teknologi digital native yang mulai diperlukan dalam pembelajaran. Lebih lanjut, kesiapan orang tua diperlukan untuk melakukan kontrol terhadap upaya adaptasi yang dilakukan oleh anak terhadap teknologi digital native sebagai media pembelajaran. Kedua, kesiapan dan keterampilan guru dalam memanfaatkan teknologi digital native dalam pembelajaran seni budaya memainkan peran penting. Guru membutuhkan keterampilan pemahaman dan pengelolaan teknologi digital native yang memadai untuk menerapkannya dalam pembelajaran. Selain itu, guru membutuhkan wawasan tentang peran pedagogis teknologi digital native dan relasinya dengan pelajaran seni budaya untuk mempermudah dalam ketercapaian tujuan pembelajaran. Oleh karenanya, perlu kematangan dan pemahaman secara spesifik terkait kebijakan, fasilitas, dan kesiapan serta keterampilan guru untuk mengintegrasikannya ke dalam proses pedagogik. Selain itu, dukungan teknis dan pengembangan profesional berkelanjutan di bidang teknologi digital native dalam pembelajaran seni budaya harus dilakukan secara berkelanjutan.

\section{Daftar Pustaka}

(ACRL), Association of College and Research Libraries. "ACRL Visual Literacy Competency Standards for Higher Education,” 2011. http://www.ala.org/acrl/standards/vi sualliteracy.

Black, Joanna, and Kathy Browning. "Creativity in Digital Art Education Teaching Practices." Art Education 64, no. 5 (2011): 19-34. https://doi.org/10.108o/ooo43125.2011 .11519140 .

Bowen, Daniel H., Jay P. Greene, and Brian Kisida. "Learning to Think Critically: A Visual Art Experiment." Educational Researcher 43, no. 1 (2014): 37-44. https://doi.org/10.3102/o013189X13512 675 .

Cannon, Michelle. Digital Media in Education: Teaching, Learning and Literacy Practices with Young Learners. London: The Palgrave Macmillan, 2018. https://doi.org/10.1007/978-3-31978304-8.

Charman, Steve, and Brian Cahill. "Journal of Applied Research in Memory and Cognition.” Journal of Applied Research in Memory and Cognition 1, no. 220020483 (2012): 171-78.

Choi, Haeryun, and Joseph M. Piro. 
"Expanding Arts Education in a Digital Age." Arts Education Policy Review 110, no. 3 (2009): 27-34. https://doi.org/10.3200/AEPR.110.3.27 -34 .

Colman, Alison. "Net.Art and Net.Pedagogy: Introducing Internet Art to the Digital Art Curriculum." Studies in Art Education 46, no. Technology Issue (2018): 61-73.

Cook-Sather, Alison, and Zanny Alter. "What Is and What Can Be: How a Liminal Position Can Change Learning and Teaching in Higher Education." Anthropology and Education Quarterly 42, no. 1 (2011): 37-53. https://doi.org/10.1111/j.15481492.2010.01109.X.

Creswell, John W. Research Design Pendekatan Kualitatif, Kuantitatif, Dan Mixed. Yogyakarta: Pustaka Pelajar, 2010.

Denzin, Norman K., and Yvonna S. Lincoln, eds. The SAGE Handbook of Qualitative Research. Fifth Edit. Los Angeles: Sage Publications, 2018. https://doi.org/10.1007/s11229-0171319-X.

Dussel, Inés, and Karin Priem. "The Visual in Histories of Education: A Reappraisal." Paedagogica Historica 53, no. 6 (2017): 641-49. https://doi.org/10.1080/o0309230.201 7.1392582 .

Gao, Shiming, and Chih ming Wang. "Crisis of the Human and the Responsibilities of Art/Education." Inter-Asia Cultural Studies 20, no. 1 (2019):

140-49. https://doi.org/10.108o/14649373.201 9.1577586.

Gehlbach, Roger D. "Art Education: Issues in Curriculum and Research." Educational Researcher 19, no. 7 (1990):

19-25. https://doi.org/10.3102/0013189X0190 o7019.
Ghavifekr, Simin, and Wan Athirah Wan Rosdy. "Teaching and Learning with Technology: Effectiveness of ICT Integration in Schools." International Journal of Research in Education and Science 1, no. 2 (2015): 175-91. https://doi.org/10.2189o/ijres.23596.

Gomis-Porqueras, Pedro, and José A. Rodrigues-Neto. "Teaching Technologies, Attendance, Learning and the Optimal Level of Access to Online Materials." Economic Modelling 73, no. May 2017 (2018): 329-42.

https://doi.org/10.1016/j.econmod.201 8.04.009.

Grierson, Elizabeth. "Art and Creativity in the Global Economies of Education." Educational Philosophy and Theory 43, no. 4 (2011): 336-50. https://doi.org/10.1111/j.14695812.2009.00550.x.

Gude, Olivia. "New School Art Styles: The Project of Art Education." Art Education 66, no. November 2017 (2013): 1-15.

Gunn, Vicky. "Attentive Outrage and Fine Art Higher Education: A Manifesto of the Liminal." Journal of Visual Art Practice 19, no. 1 (2020): 8-22. https://doi.org/10.108o/14702029.202 0.1723278 .

Henriksen, Danah, Punya Mishra, and Petra Fisser. "International Forum of Educational Technology \& Society Infusing Creativity and Technology in 21st Century Education: A Systemic View for Change Published by: International Forum of Educational Technology \& Society Infusing Creativity and Technology In." Journal of Educational Technology $\mathcal{E}$ Society 19, no. 3 (2016): 27-37.

Herawati, dan Iriaji. Pendidikan Seni Rupa. Jakarta: Direktorat Jenderal Pendidikan Tinggi Departemen Pendidikan dan Kebudayaan, 1998. 
Hicks, Laurie E. "Art Education : Thing or Device." Studies in Art Education 54, no. 2 (2019): 99-102.

Hicks, Troy, and Kristen Hawley Turner. "No Longer a Luxury: Digital Literacy Can't Wait." The English Journal 102, no. $6 \quad$ (2013): $58-65$. https://doi.org/10.4135/978141295740 3.n296.

Hudson, Tipton D. "Conversation as an Education Medium for the Age of Distraction - the 'Art of Range' Podcast." Rangelands 42, no. 1 (2020): 9-16.

https://doi.org/10.1016/j.rala.2020.01. 005 .

Kearns, Lorna R. "The Experience of Teaching Online and Its Impact on Faculty Innovation across Delivery Methods." Internet and Higher Education 31 (2016): 71-78. https://doi.org/10.1016/j.iheduc.2016. 06.005 .

Kidi, Norman, Bayu Kanigoro, Afan Galih Salman, Yen Lina Prasetio, Indrabudhi Lokaadinugroho, and Arief Agus Sukmandhani. "Android Based Indonesian Information Culture Education Game." Procedia Computer Science 116 (2017): 99-106. https://doi.org/10.1016/j.procs.2017.10 .015.

Kress, Gunther, and Theo van Leeuwen. Reading Images: The Grammar of Visual Design. London: Routledge, 2012.

Leavy, Particia. Research Design: Quantitative, Qualitative, Mixed Methods, Arts-Based, and Community-Based Participatory Research Approaches. New York: The Guilford Press, 2017.

Lee, Kyungmee. "Rethinking the Accessibility of Online Higher Education: A Historical Review." Internet and Higher Education 33 (2017): 15-23. https://doi.org/10.1016/j.iheduc.2017. o1.001.

Lin, Tzu-Bin, Victor Chen, and Ching Sing Chai, eds. New Media and Learning in the 21st Century; A Social-Cultural Perspektive. Singapore: Springer, 2015. https://doi.org/10.1007/978-981287-326-2.

Lindberg, Susanna. "Politics of Digital Learning-Thinking Education with Bernard Stiegler." Educational Philosophy and Theory 52, no. 4 (2020): $\quad 384-96$. https://doi.org/10.108o/o0131857.2019 .1586531 .

Lune, Howard, and Bruce L. Berg. Qualitative Research Methods for the Social Sciences. Ninth edit. Essex: Pearson, 2017.

Malchiodi, Cathy A., ed. Handbook of Art Therapy. New York: The Guilford Press, 2003. https://doi.org/10.1176/appi.ps.54.9.12 94-a.

Maney, J. Kevin. "The Role of Technology in Education." Handbook of Educational Policy, no. January (1999): $\quad 387-415$. https://doi.org/10.1016/b978012174698-8/50043-6.

Martin, Allan. Digital Literacy and the Digital Society. Dutch: Die Deutsche Bibliothek, 2008.

McClure, Marissa, Patricia Tarr, Christine Marmé Thompson, and Angela Eckhoff. "Defining Quality in Visual Art Education for Young Children: Building on the Position Statement of the Early Childhood Art Educators." Arts Education Policy Review 118, no. 3 (2017): $154-63$. https://doi.org/10.108o/10632913.2016 .1245167 .

Mills, Kathy Ann. "A Review of the " Digital Turn " in the New Literacy Studies." Review of Educational Research 80, no. 2 (2016): 246-71. 
Moran, Joe. Interdisciplinarity. New York: Routledge, 2002.

Morris, Christine Ballengee. "Art Education in Transition." Art Education 64, no. 5 (2011): 7-9.

Msila, Vuyisile, and Angeline Setlhako. “Teaching (Still) Matters: Experiences on Developing a Heutagogical Online Module at UNISA." Procedia - Social and Behavioral Sciences 69, no. Iceepsy 2012 (2012): 136-42. https://doi.org/10.1016/j.sbspro.2012.1 1.392.

Patton, Ryan M., and Melanie L. Buffington. "Keeping up with Our Students: The Evolution of Technology and Standards in Art Education." Arts Education Policy Review 117, no. 3 (2016): 1-9. https://doi.org/10.1080/10632913.2014 .944961.

Pianfetti, E.S. "Teachers and Technology: Digital Literacy through Professional Development." Language Arts 78, no. 255-262 (2001): 255-62.

Quinn, Robert D. "E-Learning in Art Education: Collaborative Meaning Making Through Digital Art Production." Art Education 64, no. 4 (2018): 18-24.

Rantatalo, Oscar, and Ola Lindberg. "Liminal Practice and Reflection in Professional Education: Police Education and Medical Education." Studies in Continuing Education 40, no. 3 (2018): 351-66. https://doi.org/10.108o/o158037X.201 8.1447918.

Roland, Craig. "Preparing Art Teachers to Teach in a New Digital Landscape." Art Education 63, no. 1 (2010): 17-24. https://doi.org/10.1080/00043125.201 o.11519049.

Ross, Jen. "Speculative Method in Digital Education Research." Learning, Media and Technology 42, no. 2 (2017): 21429. https://doi.org/10.1080/17439884.201 6.1160927 .

Sampurno, Muchammad Bayu Tejo. “A Case Study of Therapeutic Process Autistic Children as Performing Art in Indonesia." Advances in Social Science, Education and Humanities Research 277, no. Steach 2018 (2019): 41-44.

https://doi.org/https://doi.org/10.29 91/steach-18.2019.9.

Schweizer, C., J. De Bruyn, S. Hayen, B. Henskens, M. Rutten-Saris, and $\mathrm{H}$. Visser, eds. Handbook of Art Therapy: From the Paint. Houten: Bohn Stafleu Van Loghum, 2009.

Slota, Margaret, Maureen McLaughlin, Lorena Bradford, Julia F. Langley, and Sarah Vittone. "Visual Intelligence Education as an Innovative Interdisciplinary Approach for Advancing Communication and Collaboration Skills in Nursing Practice." Journal of Professional Nursing 34, no. 5 (2018): 357-63. https://doi.org/10.1016/j.profnurs.201 7.12.007.

Spalter, Anne Morgan, and Andries Van Dam. "Digital Visual Literacy." Theory into Practice 47, no. 2 (2008): 93-101. https://doi.org/10.108o/00405840801 992256.

Sudarsana, I. Ketut, Ayu Ratih Nakayanti, Andy Sapta, Haimah, Erwinsyah Satria, Kundharu Saddhono, G. S. Achmad Daengs, Endrayana Putut, Trisna Helda, and M. Mursalin. "Technology Application in Education and Learning Process." Journal of Physics: Conference Series 1363, no. 1 (2019). https://doi.org/10.1088/17426596/1363/1/012061.

Sugiarta, Awandi Nopyan. "Pengembangan Model Pengelolaan Program Pembela-Jaran Kolaboratif Untuk Kemandirian Anak Jalanan Di 
Rumah Singgah (Studi Terfokus Di Rumah Singgak Kota Bekasi)." Universitas Pendidikan Indonesia, 2007.

Tashakkori, A, and J Creswell. "Mixed Methodology Across Disciplines." Journal Of Mixed Methods Research 2, no. 1 (2008): 1-5.

Taylor, Pamela G, and B Stephen Carpenter. "Mediating Art Education: Digital Kids, Art , and Technology." Visual Arts Research 33, no. 2 (2016): 84-95.

Tusiime, Wycliff Edwin, Monica Johannesen, and Greta Björk Gudmundsdottir. "Teaching Art and Design in a Digital Age: Challenges Facing Ugandan Teacher Educators." Journal of Vocational Education and Training, 2020. https://doi.org/10.1080/13636820.202 0.1786439 .

Ulusman, Leyla, and Cimen Bayburtlu.
"Paradigm for Art Education; Creation Story of Jewels, Theme, Design, Artwork, 3D.” Procedia Social and Behavioral Sciences 51 (2012): $284-88$. https://doi.org/10.1016/j.sbspro.2012. o8.16o.

Villamizar, Andres Gabriel. "Examining Intersections between Visual Literacy and Digital Technologies in English Language Programs for Higher Education." Journal of Visual Literacy 37, no. 4 (2018): 276-93. https://doi.org/10.1080/1051144X.2018 .1522089 .

Weninger, Csilla. “The 'Vernacularization' of Global Education Policy: Media and Digital Literacy as Twenty-First Century Skills in Singapore." Asia Pacific Journal of Education 37, no. 4 (2017): $500-516$. https://doi.org/10.108o/02188791.2017 .1336429 . 